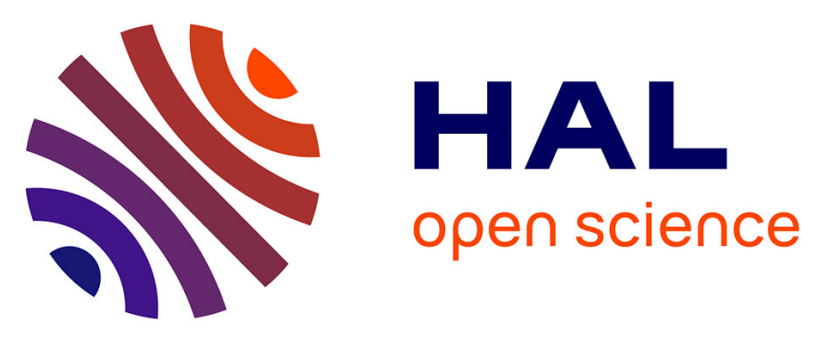

\title{
Structural and optical investigations of AlGaN MQWs grown on a relaxed AlGaN buffer on AlN templates for emission at $280 \mathrm{~nm}$
}

Xin Li, G. Le Gac, Sophie Bouchoule, Youssef El-Gmili, G. Patriarche, Suresh Sundaram, Pierre Disseix, François Reveret, Joël Leymarie, Jérémy Streque, et al.

\section{To cite this version:}

Xin Li, G. Le Gac, Sophie Bouchoule, Youssef El-Gmili, G. Patriarche, et al.. Structural and optical investigations of AlGaN MQWs grown on a relaxed AlGaN buffer on AlN templates for emission at 280 nm. Journal of Crystal Growth, 2015, 432, pp.37-44. 10.1016/j.jcrysgro.2015.09.013 . hal-01212591

\author{
HAL Id: hal-01212591 \\ https://hal.science/hal-01212591
}

Submitted on 13 Jan 2022

HAL is a multi-disciplinary open access archive for the deposit and dissemination of scientific research documents, whether they are published or not. The documents may come from teaching and research institutions in France or abroad, or from public or private research centers.
L'archive ouverte pluridisciplinaire HAL, est destinée au dépôt et à la diffusion de documents scientifiques de niveau recherche, publiés ou non, émanant des établissements d'enseignement et de recherche français ou étrangers, des laboratoires publics ou privés.

\section{(ㅇ)(1) $\$$}

Distributed under a Creative Commons Attribution - NonCommerciall 4.0 International 


\section{Author's Accepted Manuscript}

Structural and optical investigations of $\mathrm{AlGaN}$ MQWs grown on a relaxed AlGaN buffer on AlN templates for emission at $280 \mathrm{~nm}$

X. Li, G. Le Gac, S. Bouchoule, Y. El Gmili, G. Patriarche, S. Sundaram, P. Disseix, F. Réveret, J. Leymarie, J. Streque, F. Genty, J-P. Salvestrini, R.D. Dupuis, X.-H. Li, P.L. Voss, A. Ougazzaden

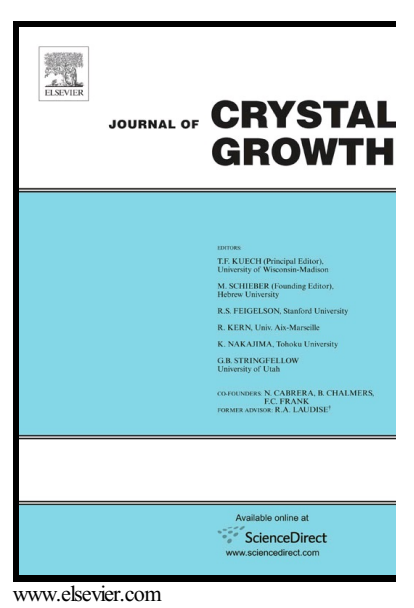

PII: $\quad$ S0022-0248(15)00566-7

DOI: $\quad$ http://dx.doi.org/10.1016/j.jcrysgro.2015.09.013

Reference: CRYS22991

To appear in: Journal of Crystal Growth

Received date: 2 July 2015

Revised date: 12 September 2015

Accepted date: 14 September 2015

Cite this article as: X. Li, G. Le Gac, S. Bouchoule, Y. El Gmili, G. Patriarche S. Sundaram, P. Disseix, F. Réveret, J. Leymarie, J. Streque, F. Genty, J-P. Salvestrini, R.D. Dupuis, X.-H. Li, P.L. Voss and A. Ougazzaden, Structural and optical investigations of $\mathrm{AlGaN}$ MQWs grown on a relaxed $\mathrm{AlGaN}$ buffer or AlN templates for emission at $280 \mathrm{~nm}$, Journal of Crystal Growth http://dx.doi.org/10.1016/j.jcrysgro.2015.09.013

This is a PDF file of an unedited manuscript that has been accepted fo publication. As a service to our customers we are providing this early version o the manuscript. The manuscript will undergo copyediting, typesetting, an review of the resulting galley proof before it is published in its final citable form Please note that during the production process errors may be discovered whic could affect the content, and all legal disclaimers that apply to the journal pertain 


\title{
Structural and optical investigations of AIGaN MQWs grown on a relaxed
}

\section{AlGaN buffer on AIN templates for emission at $280 \mathrm{~nm}$}

\author{
X. Li ${ }^{1,2}$, G. Le Gac ${ }^{3}$, S. Bouchoule ${ }^{4}$, Y. El Gmili ${ }^{2}$, G. Patriarche ${ }^{4}$, S. Sundaram ${ }^{2}$, P. Disseix ${ }^{3}$, F. Réveret ${ }^{3}$, \\ J. Leymarie $^{3}$, J. Streque ${ }^{2}$, F. Genty ${ }^{5}$, J-P. Salvestrini ${ }^{2,6}$, R. D. Dupuis ${ }^{7}$, X.-H. Li ${ }^{7}$, P. L. Voss ${ }^{1,2}$, and A. \\ Ougazzaden ${ }^{1,2, *}$ \\ ${ }^{I}$ School of Electrical and Computer Engineering, Georgia Institute of Technology, GT-Lorraine, 57070 Metz, France \\ ${ }^{2} U M I$ 2958, Georgia Tech - CNRS, 57070 Metz, France \\ ${ }^{3}$ Institut Pascal UMR 6602 CNRS, Université Blaise Pascal, 63171 Aubière, France \\ ${ }^{4}$ LPN CNRS, UPR20, 91460 Marcoussis, France \\ ${ }^{5}$ CentraleSupelec, LMOPS, EA4423, 57070 Metz, France \\ ${ }^{6}$ Université de Lorraine, LMOPS, EA 4423, 57070 Metz, France \\ ${ }^{7}$ Center for Compound Semiconductors and School of Electrical and Computer Engineering, Georgia Institute of Technology, Atlanta, \\ Georgia 30332, USA \\ *aougazza@georgiatech-metz.fr
}

\begin{abstract}
10-period $\mathrm{Al}_{0.57} \mathrm{Ga}_{0.43} \mathrm{~N} / \mathrm{Al}_{0.38} \mathrm{Ga}_{0.62} \mathrm{~N}$ multi-quantum wells (MQWs) were grown on a relaxed $\mathrm{Al}_{0.58} \mathrm{Ga}_{0.42} \mathrm{~N}$ buffer on AlN templates on sapphire. The threading dislocations and $\mathrm{V}$-pits were characterized and their origin is discussed. The influence of V-pits on the structural quality of the MQWs and on optical emission at $280 \mathrm{~nm}$ was analyzed. It was observed that near-surface V-pits were always associated with grain boundaries consisting of edge threading dislocations originating from the $\mathrm{AlN} / \mathrm{Al}_{2} \mathrm{O}_{3}$ interface. Although the high density of V-pits disrupted MQWs growth, it did not affect the internal quantum efficiency which was measured to be $\sim 1 \%$ at room temperature even when V-pit density was increased from $7 \times 10^{7} \mathrm{~cm}^{-2}$ to $2 \times 10^{9}$ $\mathrm{cm}^{-2}$. The results help to understand the origin, propagation and influences of the typical defects in $\mathrm{AlGaN}$ MQWs grown on $\mathrm{AlN} / \mathrm{Al}_{2} \mathrm{O}_{3}$ templates which may lead to further improvement of the performance of DUV devices.
\end{abstract}

\section{Keywords}

A1. Defects

A3. Metalorganic vaphor phase epitaxy

A3. Quantum wells

B1. III-nitrides

B3. DUV devices 


\section{Introduction}

Semiconductor light sources emitting in the deep ultra-violet (DUV) region have numerous applications such as sterilization, water/air purification, optical imaging systems, spectroscopy, and high density storage systems. III-nitrides are excellent candidates because of their interesting properties which include tunable band gap that covers the UV spectral range, and also include thermal and chemical stability. However, compared with InGaN-based visible laser diodes or light emitting diodes (LEDs), the efficiency of DUV light sources based on the $\mathrm{AlGaN}$ materials is much lower. One of the biggest issues is the rapid degradation of structural quality for $\mathrm{Al}(\mathrm{Ga}) \mathrm{N}$ epitaxial layers with increased $\mathrm{Al}$ content. Bulk AlN substrates could be good candidates to achieve low-threshold optically pumped DUV lasers due to small lattice mismatch with the epitaxial layers and low dislocation density below $5 \times 10^{8} \mathrm{~cm}^{-2}$ [1-3], but they suffer from high impurity absorption, high cost and limited availability. LED and laser devices were also obtained on AlN templates grown on sapphire [4,5], but threading dislocation density is still above $10^{9} \mathrm{~cm}^{-2}$, limiting performance. Besides threading dislocations (TDs), the impurity (such as oxygen) effect is greater in AlN epitaxial layers than in $\mathrm{GaN}$ due to low diffusion length of $\mathrm{Al}$ atoms (high sticking coefficient) and increased affinity of $\mathrm{Al}$ to oxidize, which cause rather high density of defects in AlGaN layers with $\mathrm{Al}$ content larger than 50\% [6,7]. Unlike the defects in InGaN/GaN MQWs which have been widely studied (even though the influence of defects on emission efficiency is still controversial) [8-13], only a few reports have focused on the study of the typical defects in metal organic vapor phase epitaxy (MOVPE) grown AlGaN MQWs on AlN templates for DUV devices and especially their influences on the optical emission [14-17].

In this work, the threading dislocations and V-shape pits in AlGaN MQWs grown on AlGaN buffer on AlN templates were characterized by different methods that allow a discussion of the potential origin of dislocations and V-pits. MQWs samples with different defect densities were prepared in order to study the optical influences of the defects on DUV emission at $280 \mathrm{~nm}$.

\section{Experiments}

The growth was performed in an MOVPE T-shape reactor [18] at $1000{ }^{\circ} \mathrm{C}$ under 100 Torr. Hydrogen was used as carrier gas. Trimethyl-aluminum (TMAl), thrimethyl-gallium (TMGa) and $\mathrm{NH}_{3}$ were used as precursors for aluminum, gallium and nitrogen, respectively. Two types of AlN templates grown on c-axis sapphire [20] were used as substrates, one with high dislocation density (template \#1) and the other with low dislocation density (template \#2). 10-period $\mathrm{Al}_{0.57} \mathrm{Ga}_{0.43} \mathrm{~N} / \mathrm{Al}_{0.38} \mathrm{Ga}_{0.62} \mathrm{~N}$ MQWs were grown on relaxed $\mathrm{Al}_{0.58} \mathrm{Ga}_{0.42} \mathrm{~N}$ buffer on these two types of AlN templates [19]. The samples grown on the same type of template in different runs have comparable defect density, which confirmed reproducibility. Identical or similar structures grown on different types of templates (template \#1 and template \#2) have significant difference in V-pit density and they were chosen in order to study the influences of 


\section{ACCEPTED MANUSCRIPT}

defects on optical properties of MQWs emitting in the deep UV region.

The structural characterizations of the MQWs were carried out using high-resolution X-ray diffraction (XRD) measurements in a Panalytical X'pert Pro MRD system with $\mathrm{Cu} \mathrm{K} \alpha$ radiation. Cross-sections and plan-views of the samples were investigated by high-angle annular dark field scanning transmission electron microscopy (HAADF-STEM) and high resolution transmission electron microscopy (HRTEM), and the TEM lamellas were prepared using focused ion beam (FIB) etching. Surface morphology was characterized by scanning electron microscopy (SEM). The optical properties were investigated by transmission, temperature-dependent photoluminescence (PL) and depth-resolved cathodoluminescence (CL). The PL measurements were done from $5 \mathrm{~K}$ to $275 \mathrm{~K}$ with a $\mathrm{cw}$ laser $(266 \mathrm{~nm})$ and a weak excitation power of $\sim 1 \mathrm{~W} / \mathrm{cm}^{2}$ in order to maintain the thermal equilibrium condition and to avoid saturation of emission intensity. The spot diameter of PL is around $100 \mu \mathrm{m}$ at maximum. For transmission measurements, the size of probed area is around $0.02 \mathrm{~mm}^{2}$.

\section{Results and discussions}

10-period $\mathrm{Al}_{0.57} \mathrm{Ga}_{0.43} \mathrm{~N}(10 \mathrm{~nm}) / \mathrm{Al}_{0.38} \mathrm{Ga}_{0.62} \mathrm{~N}(1.5 \mathrm{~nm})$ MQWs grown on a relaxed $\mathrm{Al}_{0.58} \mathrm{Ga}_{0.42} \mathrm{~N}$ buffer $(\sim 630 \mathrm{~nm})$ were designed to preserve E-field $\perp$ c polarized emission (which will be referred to as TE polarization) at $280 \mathrm{~nm}$ and work around the problem related to switching of the valence band state symmetry for high aluminum compositions, and more details can be found in Ref. [19]. The sample grown on template \#1 is labeled as sample \#1 and the other grown on template \#2 is labeled as sample \#2. Figure 1 shows $\left(\begin{array}{llll}0 & 0 & 0 & 2\end{array}\right)$ 2theta-omega scans of both samples. Satellite diffraction peaks (SL) can be observed which indicate good periodicity of MQWs. Based on (1 1 - -2 4) reciprocal space mapping, the buffer containing $0.58( \pm 0.01) \mathrm{Al}$ has $70 \%$ relaxation. According to the fittings, the wells of sample \#1 contain $0.38( \pm 0.015)$ Al with thickness of $1.5 \mathrm{~nm}( \pm 0.2 \mathrm{~nm})$, while the barriers contain $0.58( \pm 0.015) \mathrm{Al}$ with thickness of $10.3 \mathrm{~nm}( \pm 0.2 \mathrm{~nm})$. For the sample $\# 2$, the wells contain $0.38( \pm 0.015)$ Al with thickness of $1.3 \mathrm{~nm}( \pm 0.2 \mathrm{~nm})$, while the barriers contain $0.58( \pm$ $0.015) \mathrm{Al}$ with thickness of $9.3 \mathrm{~nm}( \pm 0.2 \mathrm{~nm})$. The slight difference of thicknesses may be due to unintentional drift between the runs.

In order to estimate threading dislocation (TD) densities in the samples, a series of skew symmetric $\omega$ scans were done to separate tilt angle (screw threading dislocations) and twist angle (edge threading dislocations), as expressed in Eq. (1), which is particularly useful for layers with high defect densities such as AlN [21,22]:

$$
\beta^{2}=\left(\beta_{\text {twist }}^{2}-\beta_{\text {tilt }}^{2}\right) \sin ^{2} \chi+\beta_{\text {tilt }}^{2}
$$

where $\beta$ is the full width at half maximum (FWHM) angle and $\chi$ is the inclination angle between the reciprocal lattice vector and the $\left(\begin{array}{llll}0 & 0 & 0 & 1\end{array}\right)$ surface normal.

Then the screw threading dislocation and edge threading dislocation densities may be estimated by Eq. (2): 


$$
\begin{aligned}
& N_{\text {screw }}=\beta_{\text {tilt }}^{2} /\left(4.35 \times b_{c}^{2}\right) \\
& N_{\text {edge }}=\beta_{\text {twist }}^{2} /\left(4.35 \times b_{a}^{2}\right)
\end{aligned}
$$

where $\beta_{\text {tilt }}$ and $\beta_{\text {twist }}$ are the tilt and twist spreads (FWHMs). The Burgers vector of c-type TD $\left(b_{c}\right)$ is $0.4982 \mathrm{~nm}$ for $\mathrm{AlN}$ and $0.5067 \mathrm{~nm}$ for $\mathrm{Al}_{0.58} \mathrm{Ga}_{0.42} \mathrm{~N}$, and the Burgers vector of a-type $\mathrm{TD}\left(\mathrm{b}_{\mathrm{a}}\right)$ is $0.3112 \mathrm{~nm}$ for $\mathrm{AlN}$ and $0.3144 \mathrm{~nm}$ for $\mathrm{Al}_{0.58} \mathrm{Ga}_{0.42} \mathrm{~N}$.

The FWHM angles measured for AlN templates and AlGaN layers (buffer + MQWs) of two samples are shown in figure 2 . The screw and edge TD densities calculated by the method above are summarized in table 1. For both samples, extra TDs were not generated within the relaxed AlGaN buffer layers. The AlN template used for sample \#1 exhibits 3 times higher screw and edge TD densities than that used for sample \#2, and the density of pits on the surface is around 30 times higher as seen in SEM images. These holes have hexagonal shape, and the ultra-high density of the holes in sample \#1 leads to the surface inhomogeneities. On the contrary, sample \#2 with much lower pit density has a flat surface (apart from holes) with root-mean square roughness (RMS) as small as $0.5 \mathrm{~nm}$ by atomic force microscope measurements.

In order to study the origin of these holes and their influences on the MQWs growth, cross-section HAADF-STEM was performed and images of sample \#1 are shown in figure 3. In the flat area of figure 3(a), the 10-period MQWs have good uniformity and periodicity. The thickness of barriers and wells agrees with XRD simulation results. In figure 3(b), it is clearly observed that the threading dislocations originate from the nucleation layer at the interface of AlN and sapphire. After a certain thickness, the dislocations are mostly aligned along the [0 0 0 1] axis. These dislocations can form low angle grain boundaries and lead to a twist of the lattice. The V-pits near the surface are always associated to these grain boundaries. Figure 3(c) is the plan-view HRTEM image of the AlN template in which some grains with size from 50 to several hundred nanometers can be identified. The atomic resolution STEM image with higher magnification is shown in Fig. 3(d) to get rid of the Moiré fringes. These grains are separated by low-angle boundaries with small misorientation of 1 - 2 degrees. During regrowth of $\mathrm{AlGaN}$ layers and MQWs, the threading dislocations and grain boundaries propagate into the following layers and penetrate the whole structure.

By looking into the V-shape defects in figure 3(e) with higher magnification, it is seen that the apex of the holes is connected to extended defects which are c-axis oriented and inherited from the AlN layer. These lines should be edge threading dislocations or mixed threading dislocations since the image is taken along the $\left[\begin{array}{llll}1 & 1 & -2 & 0\end{array}\right]$ zone axis. The possible cause of V-defects could be that impurities tend to segregate into dislocations, which may locally impede growth resulting in a small indentation. Once the facets of slow growth planes are formed due to these indentations, a V-pit can be generated [23,24]. Compared with the sample \#2, the sample \#1 has higher edge threading dislocation density which increases the probability for forming pits.

As shown in figures 3(e) and 3(f), the facets of the holes are inclined about $62^{\circ}$ to the $\mathrm{c}$ plane, which corresponds to $\left\{\begin{array}{llll}1 & 0 & -1 & 1\end{array}\right\}$ facets. The growth rate on these planes is much slower than on the c plane [23,24], so a V-shape hollow hole is formed. Figure 3(f) is an example of 


\section{ACCEPTED MANUSCRIPT}

4-period MQWs grown for investigating the sidewall growth in a V-pit. On the V-pit sidewall which is near c-plane surface, the weak contrast of QWs can be observed. Both the thickness of wells and barriers here are almost one third of the ones grown on the c plane. This small area of QWs growth on the sidewall may lead to some additional emission wavelengths with weak intensity giving rise to main peak broadness. In the area closer to the center of the hole, the wells are merged into the barriers and cannot be identified. The V-pits interrupt the superlattice growth and may lead to non-uniformity of 2D MQWs properties.

The optical properties of sample \#1 and sample \#2 were investigated. Figure 4(a) shows the PL at $80 \mathrm{~K}$ and transmission spectrum at $77 \mathrm{~K}$. Sample \#1 shows a well-defined emission at $282 \mathrm{~nm}$. The absorption edge of the wells is at $281 \mathrm{~nm}$ and absorption edge of barriers is at $260 \mathrm{~nm}$, which is in a good agreement with the design and with the compositions determined by XRD. For the sample \#2, the PL emission is at $278 \mathrm{~nm}$ while absorption edge is $275 \mathrm{~nm}$ for the wells and $260 \mathrm{~nm}$ for the barriers. The absorption edge of sample \#2 is $6 \mathrm{~nm}$ blue-shifted which can be due to the thinner wells according to XRD fitting. The emission of sample \#1 has full width at half maximum (FWHM) of $12.5 \mathrm{~nm}$, while sample \#2 has FWHM of $7.2 \mathrm{~nm}$ indicating a lower inhomogeneous broadening, which is consistent with transmission measurements. The broadening of emission peak in sample \#1 can be caused by the local variations of thickness or composition in MQWs which occurred in the high density of V-pit sidewalls near the c-plane surface, as shown in figure 3(f).

Figure 5 shows the PL integrated intensity as function of the inverse of temperature as well as Arrhenius fitting curves. The fitting equation is as follows [25]:

$$
I_{P L}(T)=\frac{I_{0}}{1+A \exp \left(\frac{E_{A}}{k T}\right)+B \exp \left(\frac{E_{B}}{k T}\right)},
$$

where $\mathrm{I}$ is the integrated intensity with arbitrary unit, and $\mathrm{I}_{0}$ is a fitting parameter which can be seen as the integrated intensity when $\mathrm{T}$ is close to $0 \mathrm{~K}$. A and B are fitting constants for two nonradiative recombination channels: the first mechanism (channel A) is for detrapping of localized excitons which dominates in the low temperature range, and the second (channel B) is for escaping out of the wells which dominates in the high temperature range. $E_{A}$ and $E_{B}$ are corresponding activation energies for those two paths of carrier escape from localized states into the non-radiative recombination centers. The internal quantum efficiency (IQE) can be compared by defining IQE $=\mathrm{I}(\mathrm{T}) / \mathrm{I}_{0}[26,27]$. In this case, the efficiency is assumed to be $100 \%$ at $5 \mathrm{~K}$, which is reasonable since the intensity was almost constant (defined as $\mathrm{I}_{0}$ ) in the temperature range of 5 to $50 \mathrm{~K}$ indicating almost no influence of nonradiative process in this range.

Based on Arrhenius equation fitting, sample \#1 has $29 \mathrm{meV}$ for $\mathrm{E}_{\mathrm{A}}$ and $96 \mathrm{meV}$ for $\mathrm{E}_{\mathrm{B}}$. Sample \#2 has $49 \mathrm{meV}$ for $E_{A}$ and $150 \mathrm{meV}$ for $E_{B}$. There is a larger energy barrier of nonradiative processes for sample \#2. Figure 5(c) shows the IQE variation with the temperature for the two samples based on Arrhenius equation. At $77 \mathrm{~K}$, the IQE of sample \#1 decreased to $80 \%$ while sample \#2 still has an IQE of $94 \%$. This can be explained by the increased concentration of nonradiative centers caused by higher dislocation density in sample 


\section{ACCEPTED MANUSCRIPT}

\#1 $[28,29]$. In the high temperature range, the IQE of both samples drops dramatically due to the high level of dislocation densities. Near room temperature, the error bar becomes large because emission intensity is weak and the residual laser contribution to the luminescence is not negligible. Both samples have IQE of $0.5-1 \%$ near room temperature, which is in agreement with simulated value for this level of dislocation densities [30]. To increase the IQE at room temperature, the quality of AlN templates should be further improved [31] to reduce threading dislocation densities. The 30 times higher density of V-defects in sample \#1 doesn't seem to affect the PL behavior. It could be explained by the fact that the QWs are almost absent in the V-pits according to figure 3(f), in other words, the contribution of this part to the intensity (I) of main emission peak is negligible. But it should be noted that these pits may lead to current leakage as has been observed in InGaN MQWs [10] and to lower external emission efficiency of current-injected LEDs or lasers [15].

The CL spectra shown in figure 6 were collected by scanning over an area $\sim 8 \mu \mathrm{m} \times 11$ $\mu \mathrm{m}$ at room temperature, giving the average information of the sample (including flat areas and rough areas with pits). The measurements were done under excitation from $3 \mathrm{keV}$ to 7 $\mathrm{keV}$. Figures 6(a) and 6(b) show the spectra under $7 \mathrm{keV}$ which corresponds to a penetration depth of the electron beam of typically $90 \mathrm{~nm}$. Emission from wells is located at $286 \mathrm{~nm}$ with FWHM of $16 \mathrm{~nm}$ for sample \#1 and at $276 \mathrm{~nm}$ with FWHM of $13 \mathrm{~nm}$ for sample \#2. Besides the emission from MQWs, both samples show weak defect band emission at $333 \mathrm{~nm}$. By comparing the emission intensity from the wells and the defect band, the ratio of $\mathrm{I}_{\mathrm{MQWs}} / \mathrm{I}_{\text {defects }}$ is 4.5 for sample \#1 and 24 for sample \#2 which may be attributed to lower dislocation density and the existence of more flat surface area with good quality QWs which can interact with the electron beam. The comparison of FWHM between the two samples in figure 6 (c) confirms again the higher emission uniformity of sample \#2 with fewer V-pits.

\section{Conclusions}

The threading dislocations and V-shape pits in an AlGaN MQWs structure grown on AlN templates for emission at $280 \mathrm{~nm}$ were characterized by different methods. Near surface pits were associated with grain boundaries in the AlN template consisting of edge threading dislocations from the $\mathrm{AlN} / \mathrm{Al}_{2} \mathrm{O}_{3}$ interface. The density of V-pits didn't play an important role in IQE of MQWs by PL measurements, but the pits disrupted MQWs growth and may have an effect on the homogeneity of emission. The results help to understand the origin and propagation of typical defects in AlGaN MQWs grown on AlN templates and their influences on structural quality and optical properties of MQWs for DUV emission, as an indispensable step for further improving the efficiency of the DUV devices.

\section{Acknowledgment}

This work is supported by French ANR (Agence Nationale de la Recherche) in the framework of VESUVE project (ANR-11-BS03-0012). The authors would like to thank Yacine 


\section{ACCEPTED MANUSCRIPT}

HALFAYA from GTL - CNRS UMI for his help on SEM characterizations.

\section{References}

[1] M. Martens, F. Mehnke, C. Kuhn, C. Reich, V. Kueller, A. Knauer, et al., Performance characteristics of UV-C AlGaN-based lasers grown on sapphire and bulk AlN substrates, IEEE Photonics Technol. Lett. 26 (2014) 342-345.

[2] J. Xie, S. Mita, Z. Bryan, W. Guo, L. Hussey, B. Moody, et al., Lasing and longitudinal cavity modes in photo-pumped deep ultraviolet AlGaN heterostructures, Appl. Phys. Lett. 102 (2013) 171102.

[3] N.M. Johnson, B. Cheng, S. Choi, C.L. Chua, C. Knollenberg, J.E. Northrup, et al., paper presented at the 9th International Symposium on Semiconductor Light Emitting Devices, Berlin, in: 9th Int. Symp. Semicond. Light Emit. Devices, Berlin, 2012.

[4] H. Hirayama, T. Yatabe, N. Noguchi, T. Ohashi, N. Kamata, 231-261 nm AlGaN deep-ultraviolet light-emitting diodes fabricated on AlN multilayer buffers grown by ammonia pulse-flow method on sapphire, Appl. Phys. Lett. 91 (2007) 71901.

[5] X.-H. Li, T. Detchprohm, T.-T. Kao, M.M. Satter, S.-C. Shen, P. Douglas Yoder, et al., Low-threshold stimulated emission at $249 \mathrm{~nm}$ and $256 \mathrm{~nm}$ from AlGaN-based multiple-quantum-well lasers grown on sapphire substrates, Appl. Phys. Lett. 105 (2014) 141106.

[6] M.E. Hawkridge, Z. Liliental-Weber, H.J. Kim, S. Choi, D. Yoo, J.-H. Ryou, et al., Erratic dislocations within funnel defects in AlN templates for AlGaN epitaxial layer growth, Appl. Phys. Lett. 94 (2009) 171912.

[7] L.W. Sang, H. Fang, Z.X. Qin, X.Q. Wang, B. Shen, Z.J. Yang, et al., Transmission electron microscopy investigation of inversion domain boundary in $\mathrm{A} 10.65 \mathrm{Ga} 0.35 \mathrm{~N}$ grown on AlN/sapphire template, Appl. Phys. Lett. 95 (2009) 112106.

[8] M. Shiojiri, C.C. Chuo, J.T. Hsu, J.R. Yang, H. Saijo, Structure and formation mechanism of V defects in multiple InGaN/GaN quantum well layers, J. Appl. Phys. 99 (2006) 073505.

[9] H.-L. Tsai, T.-Y. Wang, J.-R. Yang, C.-C. Chuo, J.-T. Hsu, Z.-C. Feng, et al., Observation of V Defects in Multiple InGaN/GaN Quantum Well Layers, Mater. Trans. 48 (2007) 894-898.

[10] L.C. Le, D.G. Zhao, D.S. Jiang, L. Li, L.L. Wu, P. Chen, et al., Carriers capturing of $\mathrm{V}$-defect and its effect on leakage current and electroluminescence in InGaN-based light-emitting diodes, Appl. Phys. Lett. 101 (2012) 252110.

[11] F. Lin, N. Xiang, P. Chen, S.Y. Chow, S.J. Chua, Investigation of the V-pit related morphological and optical properties of InGaN/GaN multiple quantum wells, J. Appl. Phys. 103 (2008).

[12] A.M. Armstrong, M.H. Crawford, D.D. Koleske, Contribution of deep-level defects to decreasing radiative efficiency of InGaN/GaN quantum wells with increasing emission wavelength, Appl. Phys. Express. 7 (2014) 032101. 


\section{ACCEPTED MANUSCRIPT}

[13] X. Cao, K. Topol, F. Shahedipour-Sandvik, J. Teetsov, P.M. Sandvik, S.E. LeBoeuf, et al., Influence of defects on electrical and optical characteristics of $\mathrm{GaN} / \mathrm{InGaN}$-based light-emitting diodes, Proc. SPIE. 4776 (2002) 105-113.

[14] S.-R. Jeon, S.-J. Lee, S.H. Jung, S.H. Lee, J.H. Baek, H. Jeong, et al., Effect of $\mathrm{V}$-shaped defects on structural and optical properties of AlGaN/InGaN multiple quantum wells, J. Phys. D. Appl. Phys. 41 (2008) 132006.

[15] M. Moseley, A. Allerman, M. Crawford, J.J. Wierer, M. Smith, L. Biedermann, Electrical current leakage and open-core threading dislocations in AlGaN-based deep ultraviolet light-emitting diodes, J. Appl. Phys. 116 (2014) 053104.

[16] M. Shatalov, W. Sun, R. Jain, A. Lunev, X. Hu, A. Dobrinsky, et al., High power AlGaN ultraviolet light emitters, Semicond. Sci. Technol. 29 (2014) 084007.

[17] N. Kamata, A.Z.M. Touhidul Islam, M. Julkarnain, N. Murakoshi, T. Fukuda, H. Hirayama, Nonradiative centers in deep-UV AlGaN-based quantum wells revealed by two-wavelength excited photoluminescence, Phys. Status Solidi (b). 252 (2015) 936-939.

[18] A. Mircea, A. Ougazzaden, R. Mellet, Very uniform epitaxy, Prog. Cryst. Growth Charact. Mater. 19 (1989) 39-49.

[19] X. Li, S. Sundaram, P. Disseix, G. Le Gac, S. Bouchoule, G. Patriarche, et al., AlGaN-based MQWs grown on a thick relaxed AlGaN buffer on AlN templates emitting at $285 \mathrm{~nm}$, Opt. Mater. Express. 5 (2015) 380-392.

[20] X.-H. Li, Y.O. Wei, S. Wang, H. Xie, T.-T. Kao, M.M. Satter, et al., Temperature dependence of the crystalline quality of AIN layer grown on sapphire substrates by metalorganic chemical vapor deposition, J. Cryst. Growth. 414 (2015) 76-80.

[21] M.A. Moram, M.E. Vickers, X-ray diffraction of III-nitrides, Reports Prog. Phys. 72 (2009) 036502.

[22] B.N. Pantha, R. Dahal, M.L. Nakarmi, N. Nepal, J. Li, J.Y. Lin, et al., Correlation between optoelectronic and structural properties and epilayer thickness of AlN, Appl. Phys. Lett. 90 (2007) 241101.

[23] Z. Liliental-weber, Derivation of growth mechanism of nano-defects in GaN from TEM data, Japanese Soc. Electron Microsc. 49 (2000) 339-348.

[24] Z. Liliental-Weber, Y. Chen, S. Ruvimov, J. Washburn, Formation mechanism of nanotubes in GaN, Physcal Rev. Lett. 79 (1997) 2835-2838.

[25] M. Leroux, N. Grandjean, B. Beaumont, G. Nataf, F. Semond, J. Massies, et al., Temperature quenching of photoluminescence intensities in undoped and doped GaN, J. Appl. Phys. 86 (1999) 3721-3728.

[26] J. Bai, Q. Wang, T. Wang, Greatly enhanced performance of InGaN/GaN nanorod light emitting diodes, Phys. Status Solidi (a). 209 (2012) 477-480.

[27] P. Dong, J. Yan, Y. Zhang, J. Wang, C. Geng, H. Zheng, et al., Optical properties of nanopillar AlGaN/GaN MQWs for ultraviolet light-emitting diodes, Opt. Express. 22 (2014) A320.

[28] M.A. Reshchikov, H. Morkọ, Luminescence properties of defects in GaN, J. Appl. Phys. 97 (2005) 061301.

[29] A.Y. Polyakov, I.-H. Lee, Deep traps in GaN-based structures as affecting the performance of GaN devices, Mater. Sci. Eng. R Reports. 94 (2015) 1-56. 


\section{ACCEPTED MANUSCRIPT}

[30] M. Kneissl, T. Kolbe, C. Chua, V. Kueller, N. Lobo, J. Stellmach, et al., Advances in group III-nitride-based deep UV light-emitting diode technology, Semicond. Sci. Technol. 26 (2010) 014036.

[31] X.-H. Li, S. Wang, H. Xie, Y.O. Wei, T.-T. Kao, M.M. Satter, et al., Growth of high-quality AIN layers on sapphire substrates at relatively low temperatures by metalorganic chemical vapor deposition, Phys. Status Solidi (b). 252 (2015) 1089-1095.
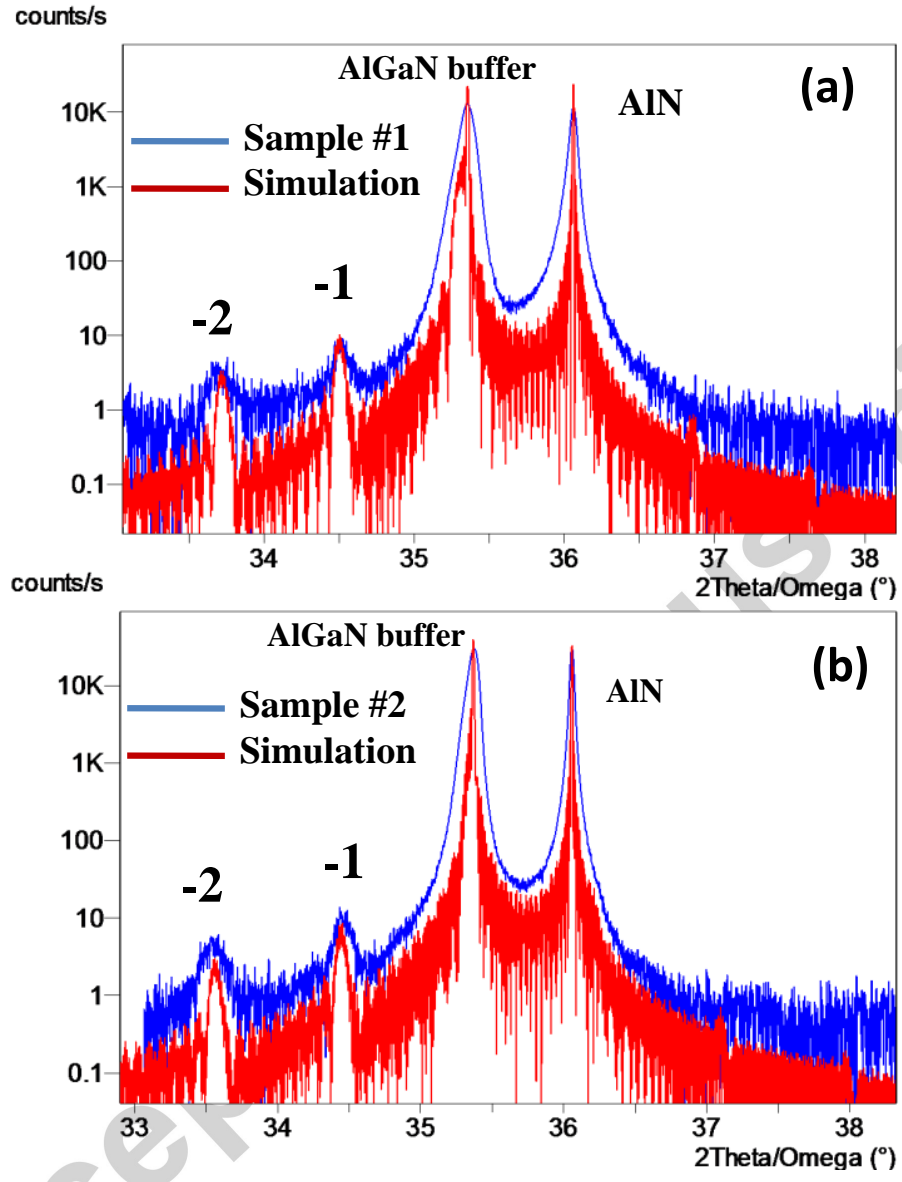

Figure 1. ( $\left.\begin{array}{llll}0 & 0 & 0 & 2\end{array}\right)$ 20- $\omega$ scans for (a) sample \#1 and (b) sample \#2 along with fitting. 


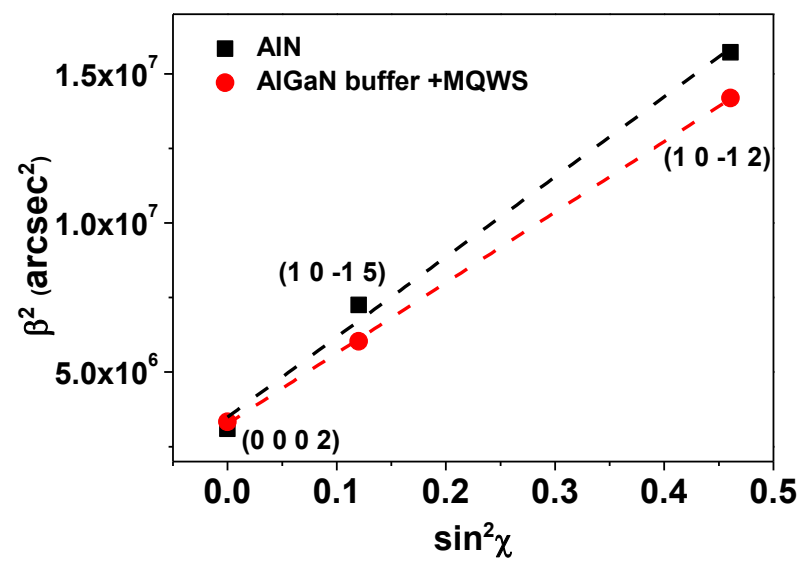

(a)

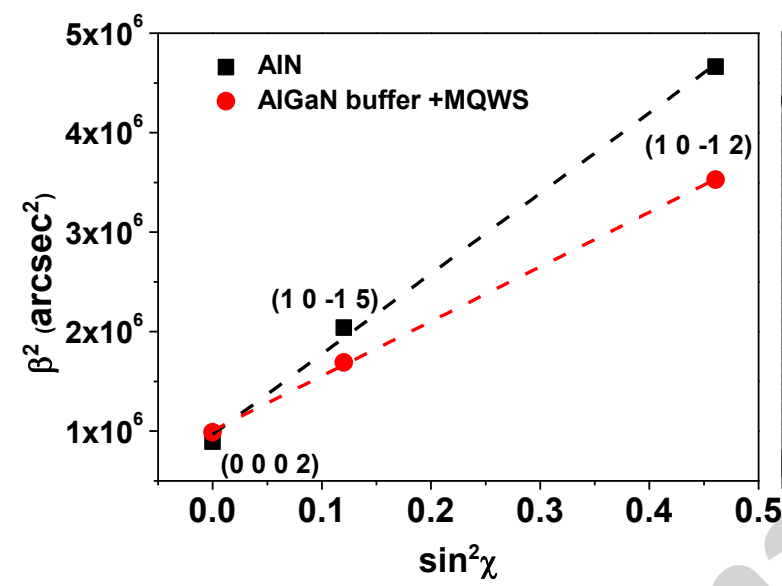

(b)

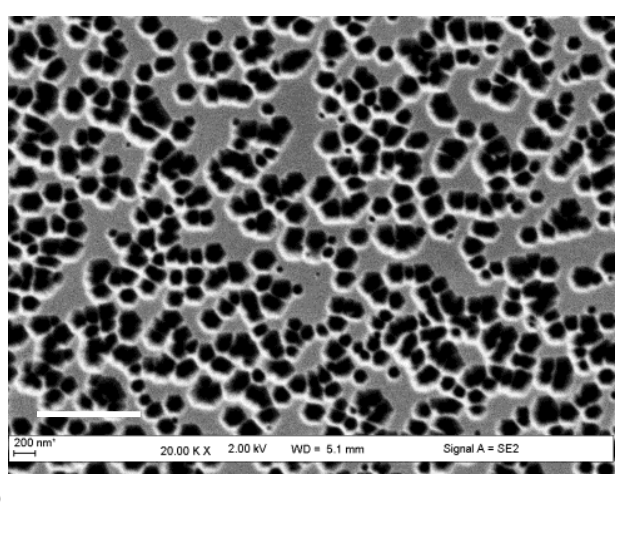

(b)

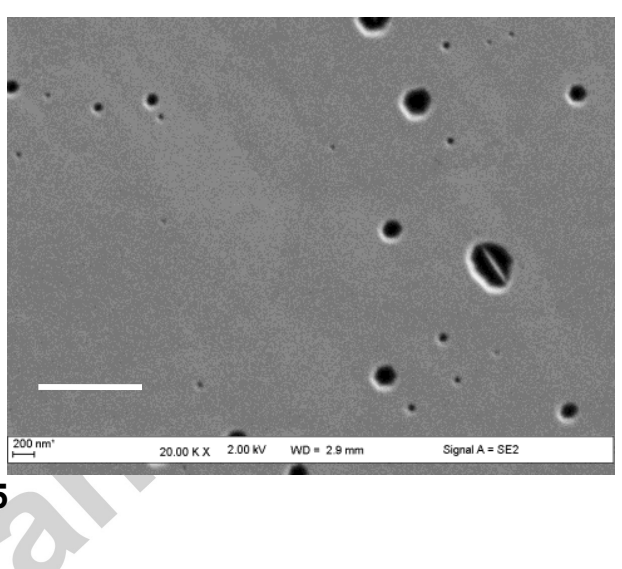

(d)

Figure 2. (a) Skew symmetric $\omega$ scans and (b) SEM images of sample \#1 grown on template $\# 1$; (c) skew symmetric $\omega$ scans and (d) SEM images of sample \#2 grown on template \#2.

Table 1. Estimated defect densities (FWHM determination and linear fitting lead to an estimated error of $\pm 8 \%$ for threading dislocations) for sample \#1 and sample \#2.

\begin{tabular}{|c|c|c|c|c|}
\hline \multicolumn{2}{|c|}{} & $\begin{array}{c}\text { Screw TDs } \\
\left(\mathrm{cm}^{-2}\right)\end{array}$ & $\begin{array}{c}\text { Edge TDs } \\
\left(\mathrm{cm}^{-2}\right)\end{array}$ & $\begin{array}{c}\text { V-pits by SEM } \\
\left(\mathrm{cm}^{-2}\right)\end{array}$ \\
\hline \multirow{2}{*}{ Sample \#1 } & AlN template & $\sim 7.3 \times 10^{9}$ & $\sim 1.7 \times 10^{11}$ & $\sim 2 \times 10^{9}$ \\
\cline { 2 - 4 } & AlGaN buffer & $\sim 6.7 \times 10^{9}$ & $\sim 1.5 \times 10^{11}$ & \\
\hline \multirow{2}{*}{ Sample \#2 } & AlN template & $\sim 2.0 \times 10^{9}$ & $\sim 4.9 \times 10^{10}$ & $\sim 7 \times 10^{7}$ \\
\cline { 2 - 4 } & AlGaN buffer & $\sim 2.1 \times 10^{9}$ & $\sim 3.5 \times 10^{10}$ & \\
\hline
\end{tabular}




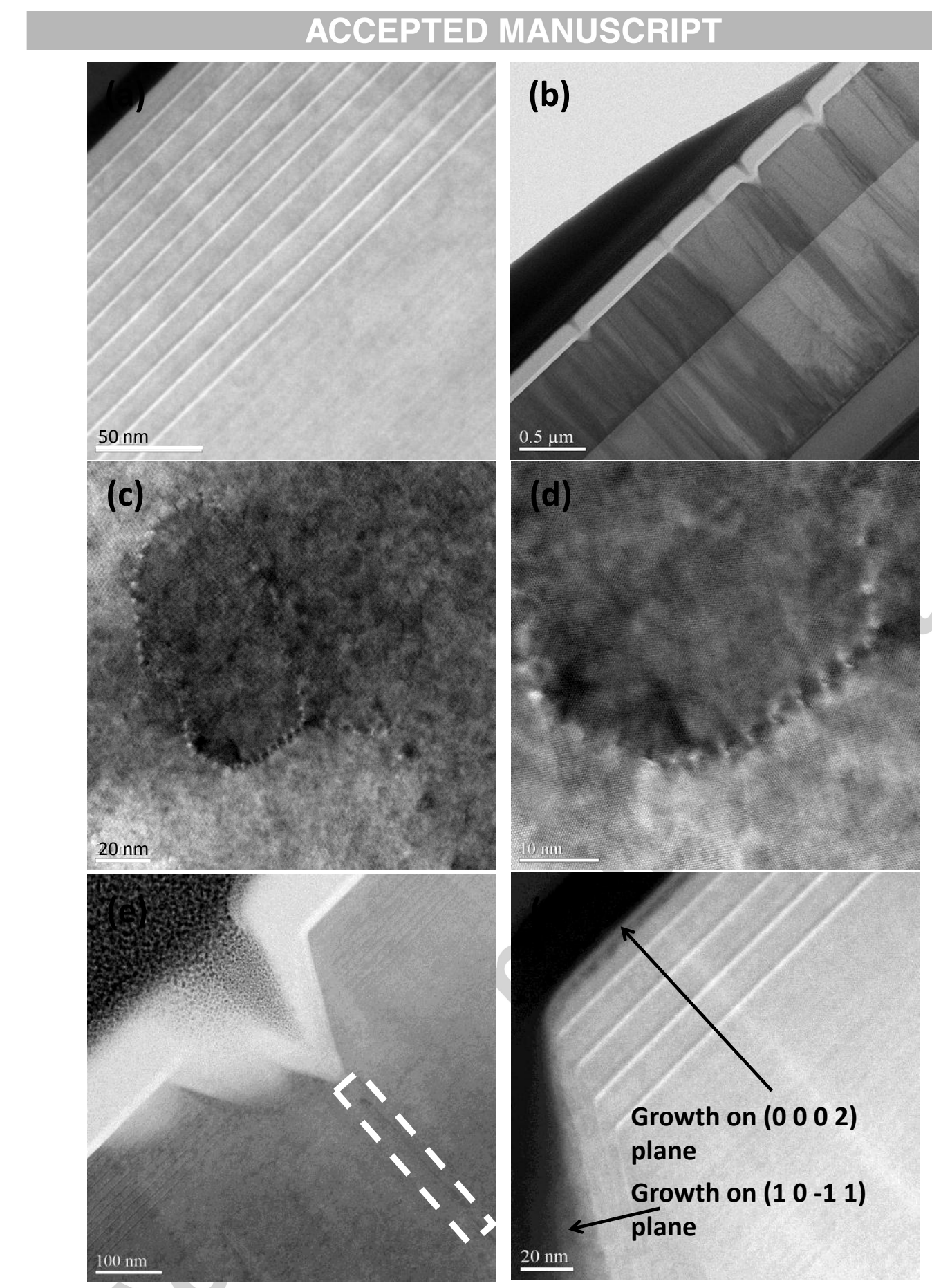

Figure 3. (a) Cross-section HAADF-STEM image of sample \#1 showing 10-period MQWs; (b) low-magnification bright field (BF) STEM image showing origin of defects; (c) plan-view HRTEM image of AlN template on sapphire showing grains; (d) plane-view high magnification image of grain boundaries; (e) high-magnification BF image on V-shape pits; (f) high-magnification HAADF-STEM image of 4-period MQWs showing the sidewall of a V-pit. 


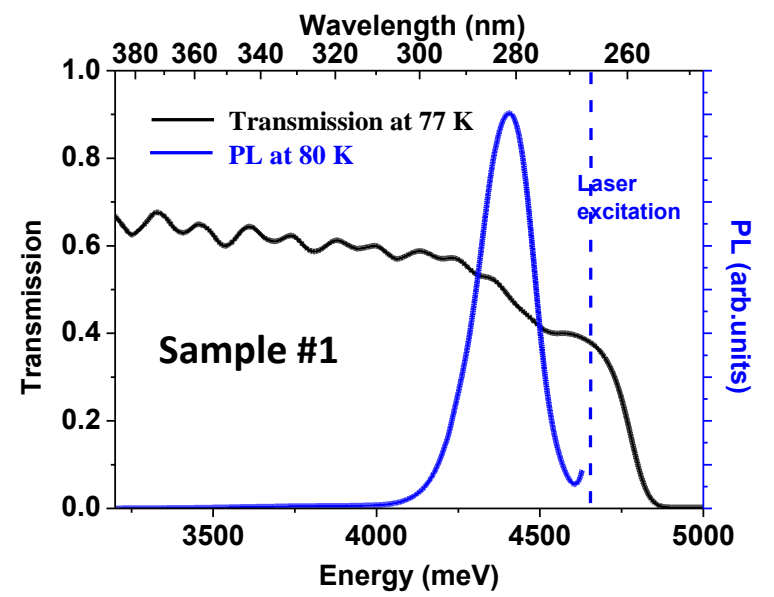

(a)

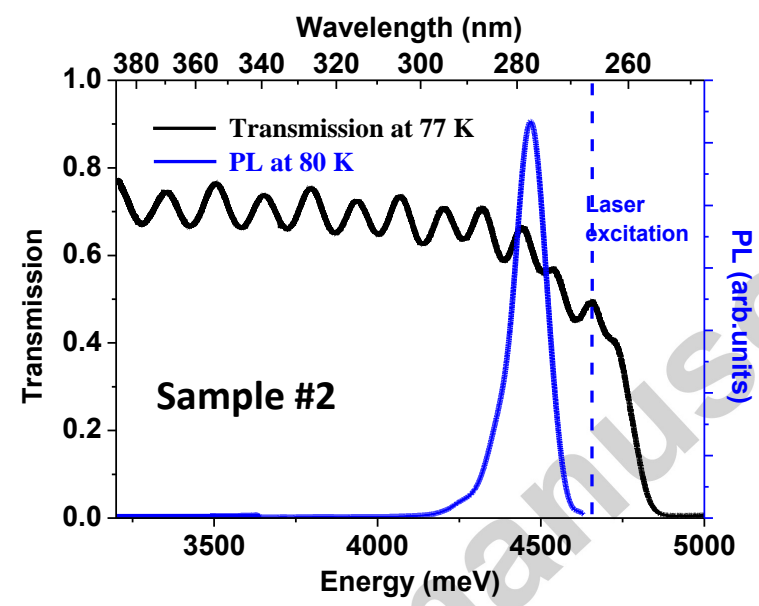

(b)

Figure 4. Transmission spectra at $77 \mathrm{~K}$ and $\mathrm{PL}$ at $80 \mathrm{~K}$ for (a) sample \#1 and (b) sample \#2. 


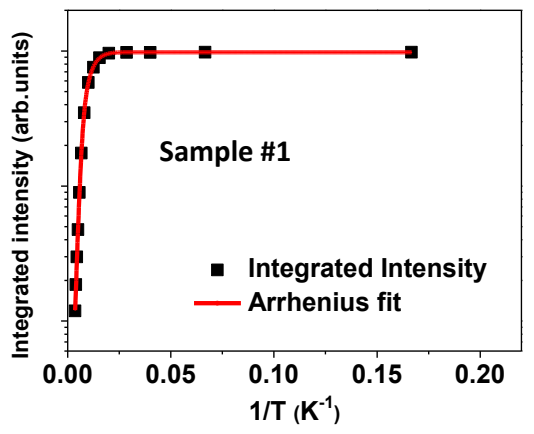

(a)

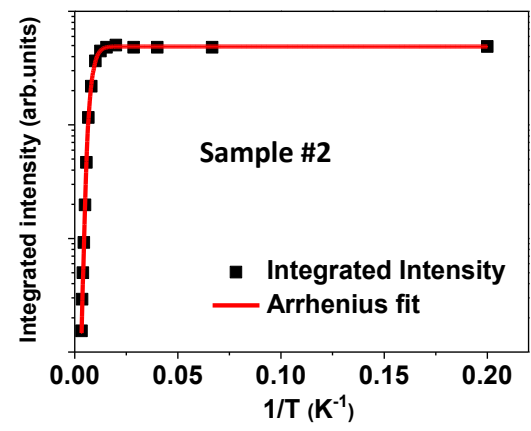

(b)

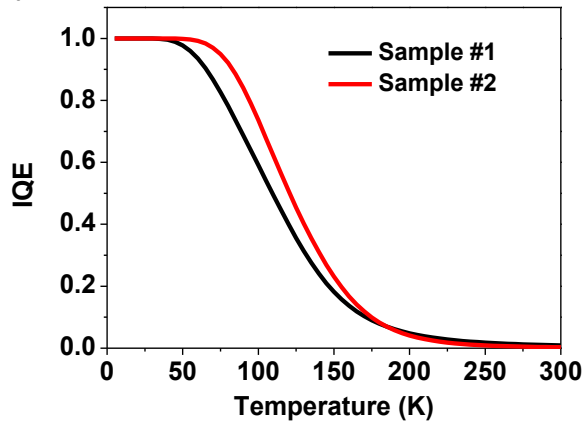

(c)

Figure 5. PL integrated intensity as function of temperature (with a $\mathrm{cw}$ laser and a weak excitation of $\sim 1 \mathrm{~W} / \mathrm{cm}^{2}$ ) and Arrhenius fitting for (a) sample \#1 and (b) sample \#2; (c) is the curve of IQE versus temperature based on Arrhenius equation fitting.

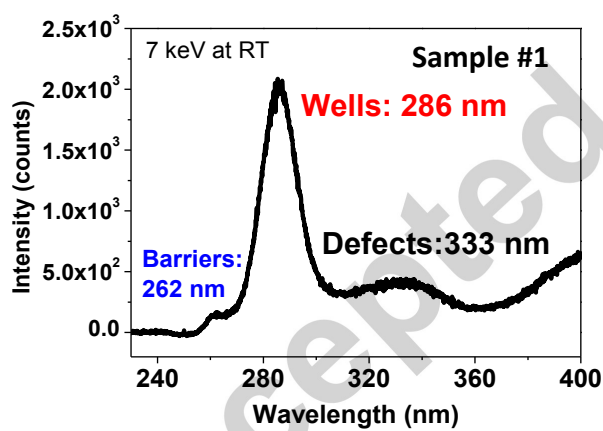

(a)

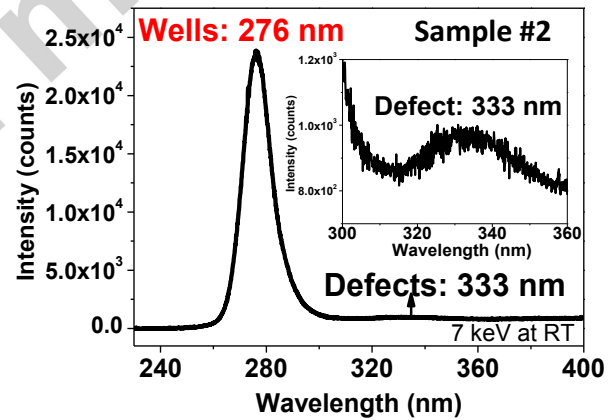

(b)

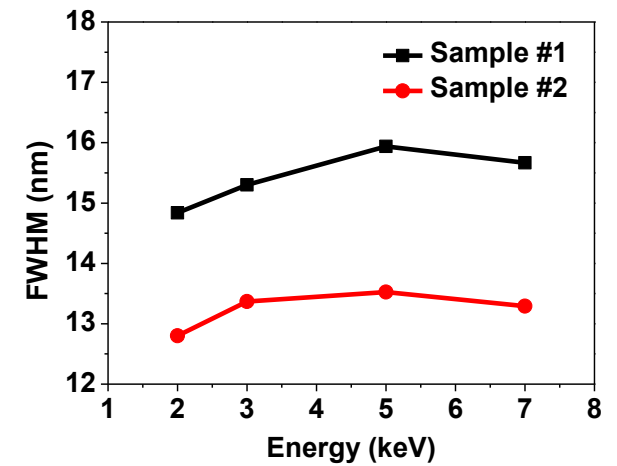

(c)

Figure 6. CL spectra under $7 \mathrm{keV}$ at room temperature for (a) sample \#1 and (b) sample \#2; (c) FWHM of QW emission peaks under different electron beam energies at room temperature. 


\section{ACCEPTED MANUSCRIPT}

- The origin of dislocations and V-defects is discussed.

- V-defects are associated with grain boundaries (edge threading dislocations).

- V-defects disrupt MQW growth and lead to unhomogeneity of emission.

- V-defect density does not affect the internal quantum efficiency. 